\title{
Multi-species transcriptome analyses for the regulation of crocins biosynthesis in Crocus
}

\author{
Oussama Ahrazem¹, Javier Argandoña' ${ }^{1}$, Alessia Fiore ${ }^{2}$, Andrea Rujas ${ }^{1}$, Ángela Rubio-Moraga', Raquel Castillo ${ }^{3}$ \\ and Lourdes Gómez-Gómez ${ }^{1 *}$ (D)
}

\begin{abstract}
Background: Crocins are soluble apocarotenoids that mainly accumulate in the stigma tissue of Crocus sativus and provide the characteristic red color to saffron spice, in addition to being responsible for many of the medicinal properties of saffron. Crocin biosynthesis and accumulation in saffron is developmentally controlled, and the concentration of crocins increases as the stigma develops. Until now, little has been known about the molecular mechanisms governing crocin biosynthesis and accumulation. This study aimed to identify the first set of gene regulatory processes implicated in apocarotenoid biosynthesis and accumulation.
\end{abstract}

Results: A large-scale crocin-mediated RNA-seq analysis was performed on saffron and two other Crocus species at two early developmental stages coincident with the initiation of crocin biosynthesis and accumulation. Pairwise comparison of unigene abundance among the samples identified potential regulatory transcription factors (TFs) involved in crocin biosynthesis and accumulation. We found a total of 131 (up- and downregulated) TFs representing a broad range of TF families in the analyzed transcriptomes; by comparison with the transcriptomes from the same developmental stages from other Crocus species, a total of 11 TF were selected as candidate regulators controlling crocin biosynthesis and accumulation.

Conclusions: Our study generated gene expression profiles of stigmas at two key developmental stages for apocarotenoid accumulation in three different Crocus species. Differential gene expression analyses allowed the identification of transcription factors that provide evidence of environmental and developmental control of the apocarotenoid biosynthetic pathway at the molecular level.

Keywords: Apocarotenoids, Carotenoids, Carotenoid cleavage dioxygenases, Crocins, Stigmas, Transcription factors

\section{Background}

Carotenoids are isoprenoid molecules that typically contain 40 carbons in their backbones and a number of conjugated double bonds that allow carotenoids to absorb light in the visible spectra, yielding yellow, orange, and red colors. Carotenoids are involved in a wide range of processes in plants, including growth and development, responses to environmental stimuli, photosynthesis (as accessory pigments) and attracting pollinators and seed dispersers; but also in animals, carotenoids control a wide

\footnotetext{
* Correspondence: Marialourdes.gomez@uclm.es

${ }^{1}$ Instituto Botánico, Departamento de Ciencia y Tecnología Agroforestal y

Genética, Universidad de Castilla-La Mancha, Campus Universitario s/n, 02071

Albacete, Spain

Full list of author information is available at the end of the article
}

range of physiological processes [1]. Carotenoids serve as precursors of apocarotenoids, which act as signaling molecules for plant development and to mediate responses to environmental cues [2]. Among apocarotenoids, crocins, glucosyl esters of crocetin, are water-soluble metabolites that accumulate at high levels in the stigma of Crocus sativus, where they function as visual signals for pollinators, due to the bright red color they provide to this tissue [3]. Crocins are also responsible for the red color of saffron spice, also known as red-gold due to the high price that it reaches in the market $(5000 € / \mathrm{kg}$, www.doazafrandelamancha.com). In addition to the contribution of crocins to the color of saffron spice, these apocarotenoids have been shown to be effective in the management of 
neurodegenerative and psychiatric disorders $[4,5]$, coronary artery diseases, bronchitis, asthma, diabetes, and cancer [6]. Therefore, crocins have the potential to regulate a broad spectrum of critical cellular functions, thus influencing human health.

Earlier, it was proposed that crocins were derived from the carotenoid zeaxanthin by a 7,$8 ; 7^{\prime}, 8^{\prime}$ cleavage [7]. More recently, the enzyme responsible for this cleavage has been elucidated $[8,9]$, and it has been shown to produce crocetin, which is the substrate of glucosyltransferase enzymes that catalyze the production of crocins [10]. The biosynthesis and accumulation of crocins in the stigma of saffron and in flowers of other Crocus species showed an increase parallel to the expression of precursor carotenogenic and apocarotenogenic genes [11-15], which represent a chromoplast-specific carotenoid pathway for crocin biosynthesis in Crocus [3]. In plants, different strategies to control carotenoid biosynthesis and accumulation have been reported [16-18], and among them, transcriptional regulation of carotenogenic gene expression has been shown to be the major mechanism by which the biosynthesis and accumulation of specific carotenoids are regulated. However, more recently, a mechanism for posttranscriptional regulation came into the spotlight [19]. Further, epigenetic regulation of genes involved in carotenoid synthesis and degradation, including histone- and/ or DNA-methylation, and RNA silencing at the posttranscriptional level affect carotenoids in plants.

A drastic change in gene expression is usually driven by transcription factors, which are master-control proteins regulating activation/suppression of gene expression through binding to specific regulatory sequences of target genes. However, the mechanisms responsible for these transcriptional controls in different plant species and tissues remain poorly understood. In addition to the role played by developmental cues, crocin biosynthesis is also affected by temperature, light and circadian rhythms [20].

Given that there is currently no reference genome available for any Crocus species, transcriptomes are key to facilitating research on secondary metabolite pathways. Efforts by independent saffron research groups have generated de novo transcriptome assemblies from different tissues of Crocus sativus, including leaves, stamens, corm, tepals, and stigmas $(105,269$ transcripts in leaf, corm, tepal, stamen and stigma [21]; 64,438 transcripts in flowers [22]; and 248,099 transcripts in tepals of Crocus ancyrensis at two developmental stages [15]). These transcriptome analyses on Crocus species [15, 21, 22] have unveiled thousands of transcription factor-coding genes, providing a foundation for investigating their involvement in apocarotenoid metabolism. However, in the specific case of saffron, data are only available from mature stigmas, thus we are lacking information on the critical stages of apocarotenoid biosynthesis [13].

A systematic comparative analysis approach for transcriptomes and crocin data is presented here to identify putative transcription factors that may affect apocarotenoid accumulation during stigma development in saffron. The pattern of accumulation of crocins and the expression of carotenoid- and apocarotenoid-related genes together with those coding for putative transcription factors has been analyzed in two key developmental stages of three Crocus species in order to clarify the mechanism influencing the biosynthesis and accumulation of these bioactive metabolites.

\section{Results and discussion}

\section{Experimental Design of Transcriptome Analysis}

Three Crocus species were selected for the identification of putative TFs involved in the metabolism of crocins (Table 1). C. sativus shows flowers similar in size to those of $C$. cartwrightianus, however its flowers show a larger stigma. C. ancyrensis is characterized by smaller flowers compared with those from the Crocus blooming in autumn, and also a much smaller stigma. In terms of crocins accumulation, $C$. sativus accumulates more crocins than the other two. It is clear that ploidy in saffron is an advantage regarding crocins production. Therefore, C. sativus was selected as the source of saffron, and C. cartwrightianus was selected as a species closely related to saffron and considered to be one of the ancestors of saffron [11, 23]. Both C. sativus and C. cartwrightianus belong to section Crocus, which are species that bloom in autumn and only accumulate crocins in the stigma tissue [24]. Finally, $C$. ancyrensis, a spring flowering species that belongs to section Nudiscapus and accumulates crocins both in stigmas and tepals, was also included $[14,25]$. We dissected stigmas of these three Crocus species at two developmental stages particularly focused on the transition from white to yellow stigmas because it is the beginning of crocetin biosynthesis and crocin accumulation (Fig. 1a). For each sample, we collected twenty stigmas to reduce possible biological variability as much as realistically possible. The presence of apocarotenoids was evaluated in the white (SI)

Table 1 Comparison of features among the Crocus species used in this study

\begin{tabular}{|c|c|c|c|c|c|}
\hline Species & Flowering period & Tepal color & Stigma color & Chromosome number $2 \mathrm{n}=$ & Distribution \\
\hline Crocus sativus & autumn & purple & red & 24 & Not known as a wild plant \\
\hline Crocus cartwrightianus & autumn & purple & red & 16 & Greece \\
\hline Crocus ancyrensis & end of winter-early spring & orange & orange & 10 & Turkey \\
\hline
\end{tabular}


a)
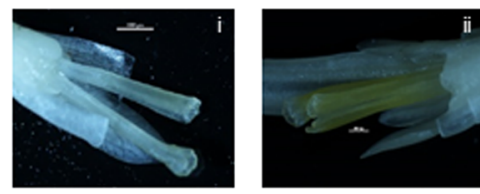

C. sativus
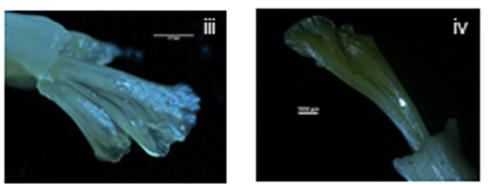

C. cartwrightianus
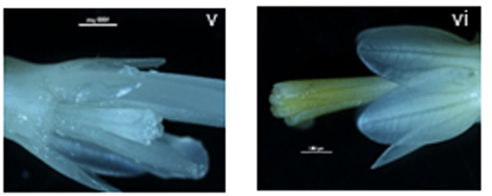

C. ancyrensis

b)

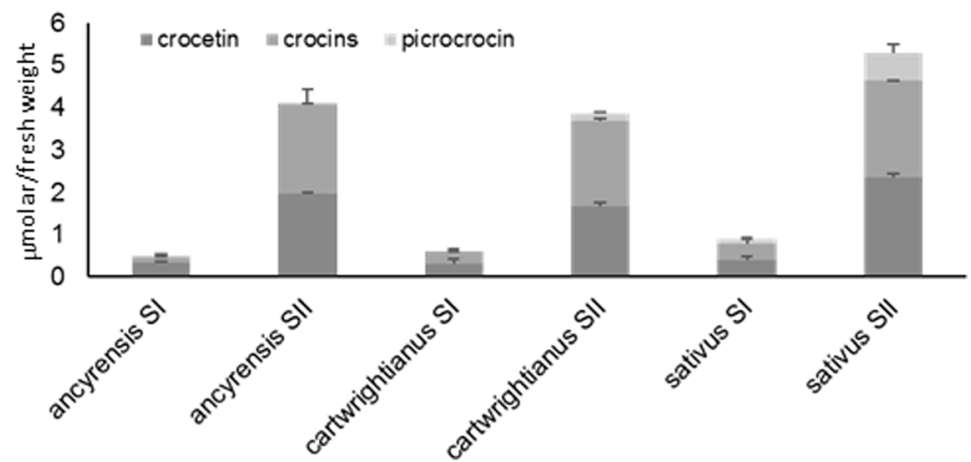

Fig. 1 Differential accumulation of crocins and accumulation in two developmental stages of stigmas from Crocus. a) Stigmas in stage I and stage II from C. sativus (i and ii), C. cartwrightianus (iii and iv), and C. ancyrensis ( $v$ and vi). b) The stigmas in stage II present a distinctive yellow colouration due to the accumulation of different apocarotenoids in this stage in all the Crocus species

and yellow (SII) stigmas of these three species by UPLC-DAD-MS analyses (Fig. 1b). For all the three species analyzed, stage SI was characterized by reduced levels of crocetin, crocins, and picrocrocin. Picrocrocin was detected in the SI stage of C. sativus and C. cartwrightianus, but not in C. ancyrensis SI stigmas (Fig. 1b), as previously observed [14]. Several explanations are possible; among them, the simplest could be the absence in this species of the glucosyltransferase transferring the sugar on the picrocrocin precursor (4-hydroxy-2,6,6-trimethyl-1-cyclohexene-1-carboxaldehyde). This glucosyltransferase has not yet been isolated from the autumn species, so its presence or absence cannot be determined yet in the spring crocuses. On the other hand, we cannot rule out the presence in these spring species of a glucosidase acting over picrocrocin in a very efficient way preventing its accumulation and therefore its detection. In the SII stage there was an increase in the content of crocetin and crocins in all the analyzed species, and again, picrocrocin was not detected in the stigmas of C. ancyrensis, as previously described [14].
In the three species, the apocarotenoid analyses revealed an increase in apocarotenoid concentration from stage I (white stigmas) to stage II (yellow stigmas).

\section{Functional annotation}

The assembled transcriptomes (Table 2) were used as queries for annotation by means of BLASTX searches based on sequence homologies in the National Center for Biotechnology Information (NCBI) (https://www.ncbi. nlm.nih.gov/) nonredundant protein database (nr), a public database, using Blast2GO with an E-value cut-off of $1 \mathrm{e}^{-06}$. For $\mathrm{GO}$ analysis, annotated unigenes were divided into three main ontologies: biological process, makes reference to the biological objective of the genes or the gene products; cellular components, makes reference to the place in the cell where the gene encoding product is active; and molecular function, defined by the biochemical activity [26]. Table 3 shows the gene ontology annotation of the assembled unigenes from the 6 transcriptomes. Among the biological process terms, protein metabolism 
Table 2 Summary for RNA-Seq reads mapping and assembly of Crocus species transcriptome sequences

\begin{tabular}{lllll}
\hline samples & Total raw reads & Clean reads & Q20\% & GC\% \\
\hline sativus-SI & $56,940,508$ & $54,756,172$ & 95.9 & 56.71 \\
sativus-SII & $63,508,296$ & $61,375,566$ & 95.56 & 47.79 \\
cartwrightianus-SI & $52,220,890$ & $50,438,172$ & 95.39 & 47.79 \\
cartwrightianus-SII & $53,966,626$ & $52,375,782$ & 95.92 & 47.32 \\
ancyrensis-SI & $51,968,850$ & $50,467,394$ & 96.1 & 46.42 \\
ancyrensis-SII & $53,403,894$ & $51,852,166$ & 96.1 & 46.62
\end{tabular}

process (20-21\%) was the most represented, followed by response to stimulus (12-15\%) and biological regulation (11\%) (Table 3). In the cellular component category, the dominant subcategory was the cell part (46-41\%), followed by the organelle (14-29\%) and the membrane (15-7\%). Under molecular function, the term binding $(42-32 \%)$ was the most represented, followed by catalytic activity (33-32\%), transport activity (5\%) and nucleic acid binding transcription factor activity (3\%) (Table 3).

We determined the 10 most abundant transcripts present in each analyzed transcriptome by the conversion of assembled read counts into normalized digital transcript levels (Fragments Per Kilobase of exon per Million fragments mapped (FPKM) (Table 4 and Additional file 1: Figure S1). Transcript abundance varied over 6 orders of magnitude, with FPKM values ranging from 0.01 to 5269.14.
Transcripts with very high transcript abundance are listed in Table 4. Among them, the translationally controlled tumor protein (TCTP) was found to be highly expressed in all the transcriptomes. TCTP belongs to a family of calcium- and tubulin-binding proteins, and it is generally regarded as a growth-regulating protein in plants [27]. A number of genes encoding for ribosomal proteins were also detected among all the transcriptomes (60S ribosomal protein L2, 60S ribosomal protein L13, and ribosomal protein S27a). Other transcripts with high abundance include histone and histone modulating enzymes, histone $\mathrm{H} 2 \mathrm{~A}$ and histone deacetylase (HDA3; HD2C) and heat shock proteins (HSP81-2, HSP81-3, HSP90-2), which probably are involved in chloroplast sorting of nuclear encoded proteins by interactions with other chaperones [28]. In the transcriptomes of $C$. sativus, several genes encoding mitochondrial proteins were found that were not present within the ten more expressed contigs of the other four transcriptomes. Among them were cytochrome $\mathrm{C}$ assembly protein, cytochrome c oxidase, subunit III (complex IV), cytochrome b, and ATPase, F0 complex. In the transcriptomes of $C$. ancyrensis and C. cartwrightianus, several lipid transfer proteins (LTP) were identified, which were also previously detected at high levels of expression in the transcriptome of C. ancyrensis [15] and in the stigmas of saffron [29]. LTPs are abundantly expressed in most plant tissues where they actively participate in lipid barrier deposition and cell

Table 3 Gene Ontology (GO) analysis of transcriptomes associated with crocins accumulation in Crocus

\begin{tabular}{|c|c|c|c|c|}
\hline Sample & Biological process & Cellular component & Molecular function & No hits \\
\hline sativus-SI & $\begin{array}{l}19 \% \\
21 \% \text { Metabolic process } \\
13 \% \text { Response to stimulus } \\
11 \% \text { Biological function }\end{array}$ & $\begin{array}{l}16 \% \\
41 \% \text { Cell part } \\
14 \% \text { Organelle } \\
13 \% \text { Membrane }\end{array}$ & $\begin{array}{l}20 \% \\
42 \% \text { Binding } \\
32 \% \text { Catalytic activity } \\
3 \% \text { Nucleic acid binding transcription factor activity }\end{array}$ & $45 \%$ \\
\hline sativus-SII & $\begin{array}{l}18 \% \\
21 \% \text { Metabolic process } \\
12 \% \text { Response to stimulus } \\
11 \% \text { Biological function }\end{array}$ & $\begin{array}{l}16 \% \\
41 \% \text { Cell part } \\
14 \% \text { Organelle } \\
15 \% \text { Membrane }\end{array}$ & $\begin{array}{l}19 \% \\
41 \% \text { Binding } \\
32 \% \text { Catalytic activity } \\
3 \% \text { Nucleic acid binding transcription factor activity }\end{array}$ & $48 \%$ \\
\hline cartwrightianus-SI & $\begin{array}{l}16 \% \\
20 \% \text { Metabolic process } \\
15 \% \text { Response to stimulus } \\
11 \% \text { Biological function }\end{array}$ & $\begin{array}{l}15 \% \\
46 \% \text { Cell part } \\
29 \% \text { Organelle } \\
7 \% \text { Membrane }\end{array}$ & $\begin{array}{l}11 \% \\
33 \% \text { Catalytic activity } \\
32 \% \text { Binding } \\
5 \% \text { Transporter activity } \\
3 \% \text { Nucleic acid binding transcription factor activity }\end{array}$ & $58 \%$ \\
\hline cartwrightianus-SII & $\begin{array}{l}16 \% \\
20 \% \text { Metabolic process } \\
14 \% \text { Response to stimulus } \\
11 \% \text { Biological function }\end{array}$ & $\begin{array}{l}15 \% \\
46 \% \text { Cell part } \\
29 \% \text { Organelle } \\
7 \% \text { Membrane }\end{array}$ & $\begin{array}{l}11 \% \\
32 \% \text { Catalytic activity } \\
32 \% \text { Binding } \\
5 \% \text { Transporter activity } \\
3 \% \text { Nucleic acid binding transcription factor activity }\end{array}$ & $59 \%$ \\
\hline ancyrensis-SI & $\begin{array}{l}17 \% \\
20 \% \text { Metabolic process } \\
15 \% \text { Response to stimulus } \\
11 \% \text { Biological function }\end{array}$ & $\begin{array}{l}15 \% \\
46 \% \text { Cell part } \\
29 \% \text { Organelle } \\
\text { 7\% Membrane }\end{array}$ & $\begin{array}{l}11 \% \\
33 \% \text { Catalytic activity } \\
32 \% \text { Binding } \\
\text { 5\% Transporter activity } \\
3 \% \text { Nucleic acid binding transcription factor activity }\end{array}$ & $57 \%$ \\
\hline ancyrensis-SII & $\begin{array}{l}16 \% \\
20 \% \text { Metabolic process } \\
14 \% \text { Response to stimulus } \\
11 \% \text { Biological function }\end{array}$ & $\begin{array}{l}15 \% \\
46 \% \text { Cell part } \\
29 \% \text { Organelle } \\
7 \% \text { Membrane }\end{array}$ & $\begin{array}{l}10 \% \\
33 \% \text { Catalytic activity } \\
32 \% \text { Binding } \\
5 \% \text { Transporter activity } \\
3 \% \text { Nucleic acid binding transcription factor activity }\end{array}$ & $59 \%$ \\
\hline
\end{tabular}


expansion [30]. In C. ancyrensis, we also found contigs with identity to late embryogenesis abundant proteins (LEA), as described earlier for C. sieberi [15]. Most LEA proteins play an important role in abiotic stress response and stress tolerance in plants [31]. In both species, the presence of highly expressed LEA transcripts could reflect the requirement in these spring-flowering species for cold to break flower bud dormancy, as observed in other flowers' buds [32].

\section{Expression of carotenogenic and apocarotenogenic genes} in white and yellow stigmas

Carotenoids are synthesized in plastids from metabolic precursors provided by methylerythritol 4-phosphate (MEP) [1]. An expression analysis of genes involved in carotenoid and apocarotenoid pathways in the three species of Crocus was performed. We started with a search for genes encoding enzymes involved in the MEP pathway. A total of eight sequences coding for putative proteins of this pathway were identified in the six transcriptomes (Fig. 2a). 1-Deoxy-D-xylulose-5-phosphate synthase (DXS) has been shown to catalyze one of the rate-limiting steps of the MEP pathway [33]. It generates 1-deoxy-D-xylulose-5-phosphate (DXP) by the condensation of pyruvate and D-glyceraldehyde 3-phosphate (Fig. 2a). DXS is typically encoded by a small gene family. High expression levels of contigs with identity to CLA1 were found in the six transcriptomes, and the expression levels increased from SI to SII (Fig. 2a). The remaining identified sequences did not show a clear repetitive pattern among the analyzed species, with the exception of hydroxymethylbutenyl diphosphate synthase (HDS), with increased expression levels from SI to SII. It has been suggested that the enzymes HDS and HDR can also contribute to the regulatory mechanisms of the MEP pathway. Several recent studies have also demonstrated that MEcPP, the substrate for HDS, is a key intermediate in the MEP pathway. This metabolite leads to a retrograde signal regulating the expression of nuclear-encoded, stress-responsive genes for plastidial proteins [34]. Carotenoid biosynthesis starts from the condensation of two geranylgeranyl diphosphate (GGPP) molecules in phytoene by phytoene synthase (PSY) (Fig. 3a) [16]. In the three species analyzed, PSY levels increased from stage SI to stage SII (Fig. 3b). Next, a series of desaturation and isomerization reactions catalyzed by phytoene desaturase (PDS), $\zeta$-carotene desaturase (ZDS), $\zeta$-carotene isomerase (Z-ISO), and carotenoid isomerase (CrtISO) lead to the biosynthesis of lycopene (Fig. 3a). All the genes encoding for these enzymes were upregulated in SII (Fig. 3b); in particular, the levels of these genes were high in SII stigmas of C. sativus (Fig. 3b). Cyclization of lycopene by lycopene $\varepsilon$-cyclase (LYC-E) and/or lycopene $\beta$-cyclase (LYC-B) produces $\alpha$-carotene and $\beta$-carotene, respectively (Fig. 3a). Only contigs with homologies to $L Y C-B$ were identified in the six transcriptomes. In Crocus species, two $L C Y$ genes have been identified, one of them being $L C Y$-2, which is chromoplast-specific [12, 14, 15]. Higher levels of expression were found for $L C Y-2$ in SII in all the species (Fig. 3b). Subsequent hydroxylation of $\alpha$-carotene and $\beta$-carotene by two nonheme carotene hydroxylases $(\mathrm{BCH}-1$ and $\mathrm{BCH}-2$ ) and two heme hydroxylases (CYP97A (Lut-1) and CYP97C (Lut-2)) generates zeaxanthin and lutein, respectively (Fig. 3a). Similarly, to LCY-2, BCH-2 is also a chromoplast-specific enzyme $[3,11]$. The expression levels of $\mathrm{BCH}-2$ increased from SI to SII. However, the levels of Lut-1 and Lut-2 decreased in C. cartwrightianus and C. ancyrensis from SI to SII, while in C. sativus the FPKM values increased from SI to SII (Fig. 3b). Further, the levels of contigs with identities to apocarotenogenic genes from

\section{a)}

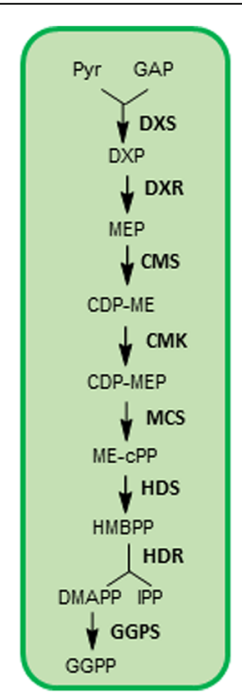

b)

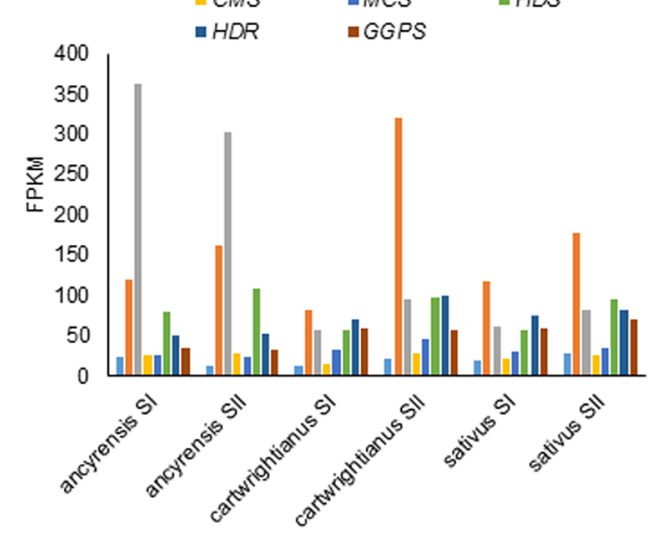

Fig. 2 Expression levels of differentially expressed unigenes assigned to the MEP pathway. a) An overview of the MEP pathway. b) Homologues genes encoding for the different enzymes of the pathway were identified in the transcriptome assembly of stigmas at stages I and II in the three Crocus species 
a)

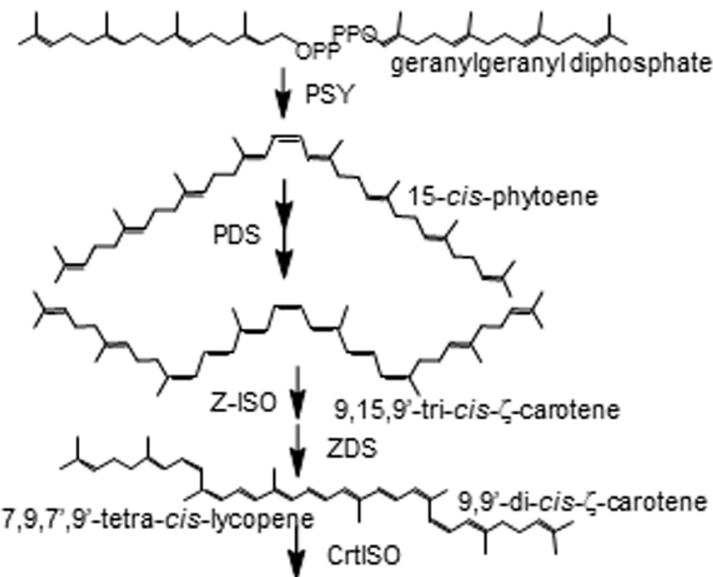

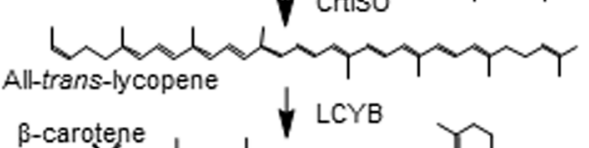

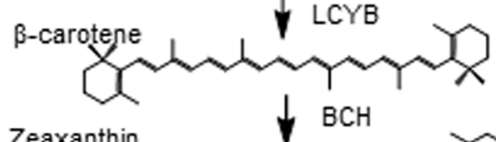

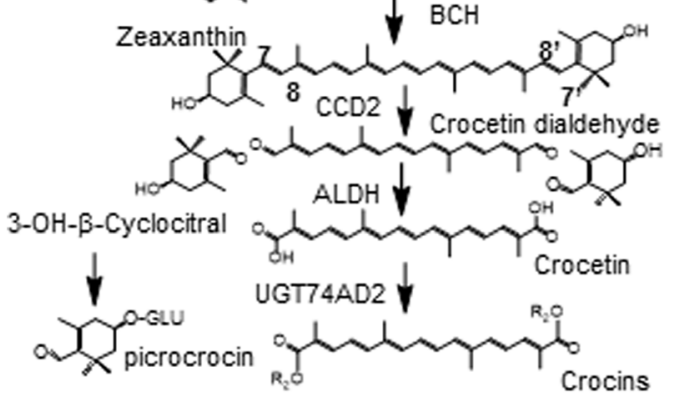

b)
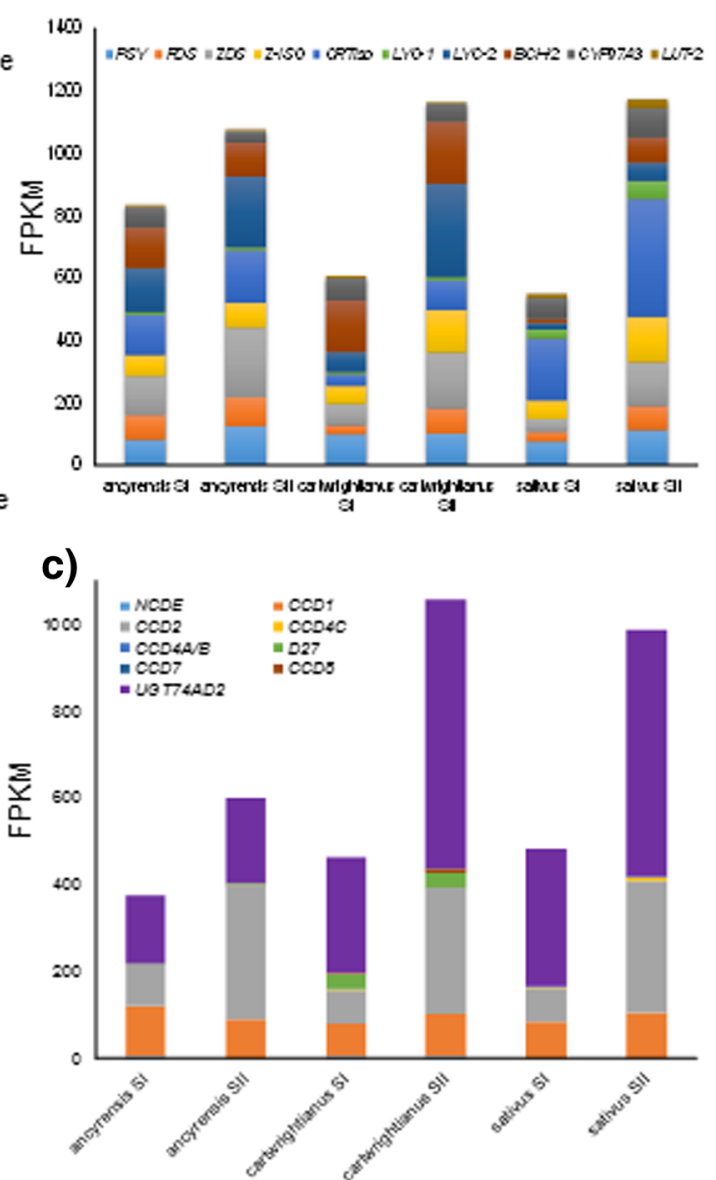

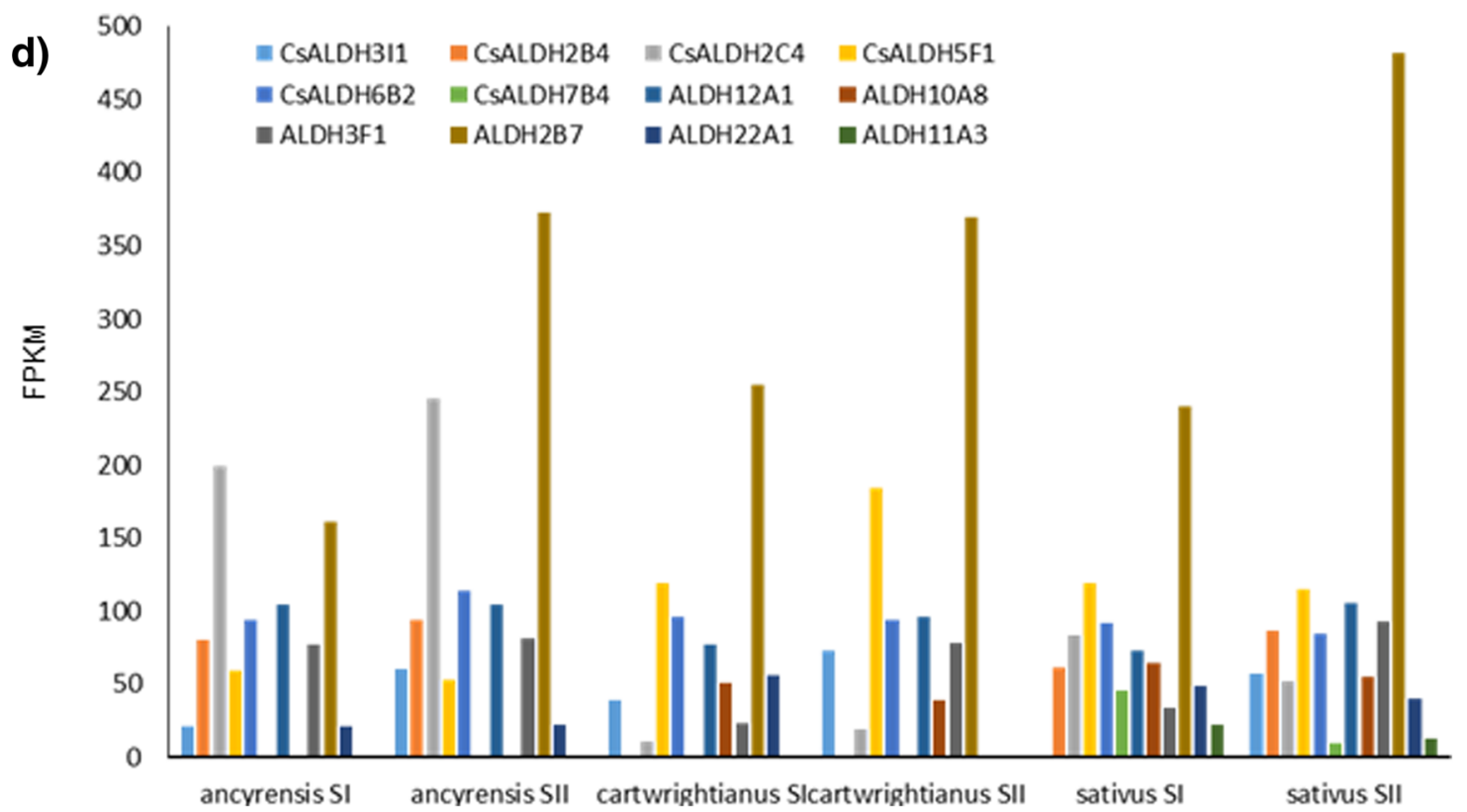

Fig. 3 (See legend on next page.) 
(See figure on previous page.)

Fig. 3 Expression levels of unigenes assigned to the carotenoid and apocarotenoid biosynthetic pathways in Crocus. a) An overview of the crocins biosynthesis pathway enzymes and metabolites in Crocus. Homologues genes encoding for the different enzymes were identified in the transcriptome assembly. b) Expression analyses of genes encoding from the enzymes of the carotenoid biosynthesis pathway identified in the transcriptomes from I and II stages of the three Crocus species. c) Expression analyses of homologues to carotenoid cleavage enzymes (CCD1, CCD2, CCD4, CCD7, CCD8 and NCED), to the $\beta$-carotene isomerase D27 and UGT74AD2 genes identified in the six transcriptomes. d) Expression analyses of ALDH genes homologues identified in the six transcriptomes analysed

saffron including $C C D 1, C C D 2, C C D 4 a / b, C C D 4 c, C C D 7$ and $C C D 8$ [35-37] and to $\beta$-carotene isomerase (D27) were also evaluated (Fig. 3c). The levels of contigs with identity to $C C D 4 a / b$ and $C C D 4 c$ were very low in all the six transcriptomes in these early developmental stages (Fig. 3c). CCD8 was only detected in C. cartwrightianus, and D27 was detected in C. cartwrightianus and in C. ancyrensis, but at very different levels (Fig. 3c). The high levels of D27 in $C$. cartwrightianus and the low levels of $C C D 8$, together with the absence of CCD7 contigs, suggested the involvement of cis- $\beta$-carotene as a substrate for other enzymes [38]. Finally, the contigs with the highest FPKM values correspond to those encoding CCD1 and CCD2 enzymes. While CCD1 values remain almost stable between the two developmental stages (Fig. 2c), CCD2 levels increased more than 2.5-fold in C. ancyrensis, and fourfold in C. cartwrightianus and C. sativus, from SI to SII (Fig. 3c). The levels of contigs encoding UGT74AD2, the enzyme that catalyzes the glucosylation of crocetin [10], were also evaluated. In all three species, the levels increased from SI to SII at least twofold (Fig. 3c) showing a positive correlation with crocins accumulation. Further, all the contigs encoding putative aldehyde dehydrogenase (ALDH) enzymes were also analyzed (Fig. 3d). Several ALDH enzymes have been characterized in saffron previously [39-41], suggesting the promiscuity of ALDH enzymes for crocetin transformation [42]. Different FPKM values were observed for a total of 12 contigs encoding ALDHs in saffron, C. cartwrightianus and C. ancyrensis. The highest values were observed for CsALDH2B7 (KU577906.2), which also increased its levels from SI to SII (Fig. 2d). The other ALDHs showed variable levels among the three species analyzed and between the two developmental stages (Fig. 3d). CsALDH3IH (KU577904) and CsALDH2B4 (KU577907), have been previously shown to catalyze the conversion of crocetin dialdehyde to crocetin in vitro $[40,41]$; however, due to the reduced expression of the respective genes in SI and SII stigmas, we doubt that either of these proteins is specifically responsible for the conversion of crocetin dialdehyde to crocetin. By contrast, ALDH2B7 was highly expressed in the analyzed stigmas and showed co-expression with CCD2.

\section{Major transcription factor families related to apocarotenoid accumulation}

In this study, 590 and 617 TFs were identified in the white (SI) and yellow (SII) transcriptomes of saffron, respectively, and those TFs belong to $102 \mathrm{TF}$ families (Additional file 2: Table S1). The basic helix-loop-helix (bHLH) family was the dominant TF family in both stages, having 53 and 39 TFs in the white (SI) and yellow (SII) stages, respectively (Additional file 2: Table S1). The bHLH proteins are a superfamily of TFs found throughout eukaryotic organisms that bind to DNA as a dimer and are characterized by the presence of a 50-60 amino acid bHLH domain. They are involved in a myriad of regulatory processes, including modulation of secondary metabolism pathways, epidermal differentiation, and responses to environmental factors in plants [43, 44]. The MYB family was the second major TF family in both stages, with 29 and 36 TFs in the white and yellow stages (I and II), respectively (Additional file 2: Table S1). In addition, MYB-like TFs were also detected at relatively high levels, 21 and 15 in stages I and II, respectively (Additional file 2: Table S1). MYB represents a family of proteins that include a 52 amino acid conserved MYB DNA-binding domain and are involved in cell cycle regulation, cell proliferation, development, hormone signaling, and abiotic stress responses [45]. The next most abundant group was represented by TFs with the ZIP domain: HD-ZIP (21 in SI and 19 in SII) and bZIP (20 in SI and 22 in SII). The basic leucine (Leu) zipper (bZIP) TF family is characterized by a conserved 60-80 amino acid bZIP domain. These TFs are involved in organ and tissue differentiation, seed maturation, floral transition and initiation, vascular development and in signaling in response to abiotic/biotic stimuli [46]. The HD-ZIP proteins have an HD domain that binds the DNA and a Zip located downstream of the HD, which acts as a dimerization motif. TFs from this family have essential functions for plant development and plant responses to environmental conditions [46].

Among all these TFs, a total of 131 TFs were found to be significantly differentially expressed at $P \leq 0.001$, FDR $\leq 0.05$, and $\log 2 \mid$ fold change $\mid>2$ in relation to the color change; of these, 64 were upregulated and 67 were downregulated in stage II. In a previous report on saffron stigmas at anthesis, a total of 92 TFs were found to be upregulated in this tissue compared with their expression in leaves, corm, petals and stamens [21]. A list of the most up- and downregulated TFs in yellow samples compared to the white stage are presented in Fig. 4 and in Additional file 2: Tables S2 and S3, respectively. 

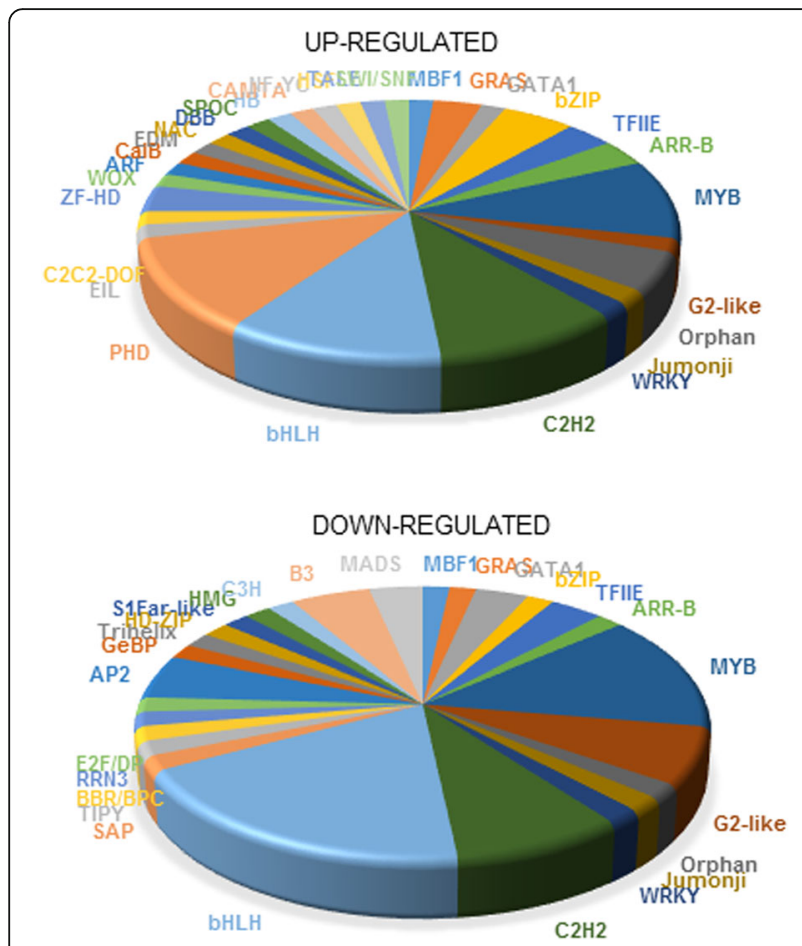

Fig. 4 Transcription factor families identified in the differential expression analyses of the two stigmas transcriptomes of saffron. Transcription factors (TFs) were identified by sequence comparison of saffron transcripts with the Plant Transcription Factor Database (PInTFDB) by BLASTX, using default parameters and cut-off E-value of $1 \mathrm{e}^{-5}$

The expression of a homolog to AT2G42680.1 (ATMBF1A), one of three genes in A. thaliana encoding multi-protein bridging factor 1 , a highly conserved transcriptional coactivator, was increased by more than 5 -fold. This was followed by a homolog of an unknown PHD finger family protein, encoding the gene AT2G18090, with an increase of over 4-fold; and by EIL (AT2G27050), which together with PIFs regulates growth in response to hormone and light signals [47]. In addition, other upregulated TFs were involved in circadian and light responses, such as PRR7 and PRR9 [48], which are partially redundant, are essential components of a temperature-sensitive circadian system; CCA1 and LHY, which have a positive effect on PRR7 expression levels [48]; and AT1G59940, which is rapidly induced by cytokinin, and is involved in red-light signaling, acting redundantly with ARR3 in the control of circadian period [49]. Previously, two TFs named CsULT1 and CsSAP09 were identified as regulators of apocarotenoid deposition in saffron [50, 51]. However, the expression patterns of both genes in mature flowers were not associated with apocarotenoid deposition or CCD2 expression $[8,13]$, and neither CsULT1 or CsSAP09 were present among the upregulated TFs.
Among the downregulated genes, ASML2, which acts as a transcriptional activator of a set of sugar-inducible genes, was downregulated 6-fold [52], followed by a 5-fold downregulation of the bHLH TF AT1G09250, a negative regulator of cell elongation [53]; and AT1G06170, probably involved in the development of anthers.

\section{Identification of common, differentially expressed TFs among the Crocus species}

The differentially expressed TFs identified in the saffron transcriptomes were investigated in the transcriptomes of the SI and SII stages of C. cartwrightianus and C. ancyrensis, in order to determine the presence of common TFs among the three species upregulated in the SII stages. Only 11 TFs that were previously identified as upregulated in the saffron SII transcriptome were found to be upregulated in C. cartwrightianus and $C$. ancyrensis SII stage transcriptomes. These TFs included homologs to ARF8, SPATULA, AT4G02720, Methylene Blue Sensitivity (MBS1), Homeobox-2 (HB-2), XRN3, Inducer of C-repeat binding factor (CBF) Expression 1 (ICE1), ALFIN, AT2G31410, AT5G28150 and Nuclear Factor YC (NF-YC). Auxin Response Factors (ARFs) contain a B3-DNA binding domain in the $\mathrm{N}$-terminal region and mediate responses to auxin [54]. ARF8, together with ARF6, coordinates the transition from immature to mature, fertile flowers [55]. The overexpression of ARF5 from sweet potato significantly increased the content of carotenoids in transgenic Arabidopsis [56]. Previous studies demonstrated that in Arabidopsis, ARF5 affected lateral organ development, primary root initiation, cotyledon development and flower primordium initiation, while in tomato, ARF5 controlled fruit set and development [57]. A study on transcriptome profiling during the development of tomato fruits revealed a correlation between carotenoid content and ARF 4 and 6 expression levels [58]. In a similar study, an ARF TF was identified in orange-fleshed sweet potato [59]. The identified ARF in the present study showed 64 and $60 \%$ identity with tomato and Arabidopsis ARF8, respectively. Furthermore, in both plants, ARF8 has been reported to regulate fertilization and fruit development [60]. SPATULA (AT4G36930) is a bHLH (basic helix-loop-helix) TF involved in generating the septum, style and stigma in the female flower [61]. The TF encoded by AT4G02720 interacts with ARGONAUTE (AGO) RNA-binding protein, involved in RNA silencing [62] but also promotes the transcription of certain genes [63]. MBS1 (AT3G02790) has been shown to act downstream of $\beta$-cyclocitral, a $\beta$-carotene oxidation product, in singlet oxygen signaling [64]. In saffron stigmas, $\beta$-cyclocitral amounts increased from the earlier stages, reaching the highest level in the red stage, and decreasing afterwards [13]. $\beta$-cyclocitral also induces the expression of $C C D 2$ in saffron [20]. In addition, MBS1 interacts with the TFs MYB100 and MYB107, involved in flavonoid downregulation and suberin deposition, respectively 
[65] (Additional file 1: Figure S2). Another protein involved in retrograde signaling is XRN3, which plays a role in the processing and degradation of several classes of nuclear RNAs, including some involved in drought and high light stress [66], and acts as posttranscriptional gene silencing (PTGS) suppressors but also induces transcription [67]. Interestingly, XRN3 is also involved in the retrograde pathway between chloroplast and nucleus [68]. Homeobox-protein $2(\mathrm{HB}-2)$ is a regulator that processes light signals from phytochromes to alter morphogenesis during shade avoidance responses, and its overexpression causes long hypocotyls and reduced leaf expansion, as observed in etiolated seedlings [69]. In maize, rice and Arabidopsis, this TF is co-expressed with PSY1 [70]. ICE1 encodes a MYC-type bHLH transcription factor directly implicated in the major cold acclimation pathway [71]. The analyzed Crocus species begin their vegetative and reproductive growth coincident with an appreciable decrease of temperature, being able to tolerate temperatures below $-18^{\circ}$ $\mathrm{C}$ [72]. In addition, $C C D 2$ expression is induced by low temperatures, and low-temperature-responsive elements are present in its promotor [20]. Further, in potato tubers it has been shown that the reaction product resulting from carotenoid cleavage dioxygenase 4 (CCD4) activity has a role in temperature sensing in the plant [73]. Alfin is a family of proteins that bear an Alfin domain and a PHD domain at their N- and C-terminus, respectively, and bind to G-rich elements (GTGGNG or GNGGTG). The PHD domains are reported to bind to histone H3K4me3 peptide with varying methylation state preferences and binding affinities [74]. Among the histone H3 methyltransferases, SDG8 preferentially binds monomethylated H3K4 (H3K4me1), acting as an epigenetic regulator of carotenoid biosynthesis [75, 76]. The Alfin TFs are important regulators of plant development and are also involved in cellular phosphate homeostasis, a process in which other apocarotenoids, the strigolactones, are implicated [77]. NF-YC is a TF widespread in plants, animals, and other eukaryotes, and is also termed CCAAT Binding Factor (CBF) and Histone-Associated Protein5 (HAP5). The NF-Y complex consists of the subunits NF-YA, NF-YB, and NF-YC (Additional file 1: Figure S2), all of which are necessary for binding to the CCAAT box in the promoter regions of its target genes to regulate their expression [78]. NF-YC TFs function as important mediators of epigenetic marks in different plant developmental stages, implying an important function of these proteins in epigenetic regulation in plants. Arabidopsis NF-YCs mediate light-controlled hypocotyl elongation via modulation of histone acetylation [79]. One gene encoding geranylgeranyl diphosphate synthase 1 (GGPS1) is among the predicted functional partners of NF-YC (Additional file 1: Figure S2). Finally, AT2G31410 and AT5G28150 have no function defined, although the predicted functional partners of AT2G31410 include proteins involved in rRNA processing (Additional file 1: Figure S2).

\section{Expression analysis of the shared TFs in vegetative and reproductive tissues}

The 11 upregulated TFs identified in the 3 Crocus species were selected for qRT-PCR analysis in different tissues of saffron, including the stigma tissue. The sequences of the primers used for qRT-PCR are listed in Additional file 2: Table S4. The expression levels of ARF8, AT4G02720, SPATULA, ICE1, ALFIN, NF-YC, and XRN3 were higher in the red stigmas compared with the expression levels in roots, leaves and corm (Fig. 5). By contrast, MBS1, $\mathrm{HB}-2$ and AT5G28150 showed higher expression levels in the corm, and AT2G31410, in the roots (Fig. 5). Of those contigs with higher expression levels in the stigma, $A R F 8$, SPATULA, ICE1, ALFIN, NF-YC, and XRN3 showed significant expression in the stigma compared with expression in the other tissues tested.

\section{Conclusions}

In this study, we sequenced and assembled new transcriptome data from three Crocus species in two key stigma developmental stages for apocarotenoid biosynthesis and accumulation. The six transcriptomes obtained perfectly complement previous transcriptomes of saffron tissues [21, 22], providing new data of the earliest developmental stages in stigma development, when crocetin, crocin and picrocrocin biosynthesis begin [13]. A positive correlation among DXS-CLA1, PDS, ZDS, Z-ISO, CrtISO, LYC-B, BCH-2, $C C D 2$, and $U G T 74 A D 2$ expression levels and apocarotenoid levels was observed in the three species. Therefore, the formation from phytoene to crocetin, and from crocetin to crocins appears to be principally under transcriptional regulation [3]. In emphasizing transcription factors, we compared the data from six transcriptomes in order to identify candidate regulators impacting apocarotenoid accumulation. Information on the spatiotemporal pattern of gene expression/metabolite accumulation can facilitate the understanding of gene function and the generation of a hypothesis for apocarotenoid biosynthesis control at the transcriptional level. We have identified 11 TFs that are expressed in the stigma tissue and correlated with apocarotenoid levels in the three species under study. These TFs belong to the ARF, bHLH, C2H2, HB, CBF/DREB1, ALFIN, and NF-YC families. Seven of them showed gene expression patterns that suggested a direct participation in the regulatory network influencing apocarotenoid profiles and content, and are involved in a complex network influenced by environmental factors and developmental stages known to regulate carotenoid accumulation in plants. Among these TFs, we found TFs involved in flower and fruit development, retrograde signaling, epigenetic modifications, and light and cold responses. The link between flower or fruit development and carotenoid accumulation in different plant species is associated with the process of chromoplast biogenesis [80, 81]. Chromoplast development in saffron is 

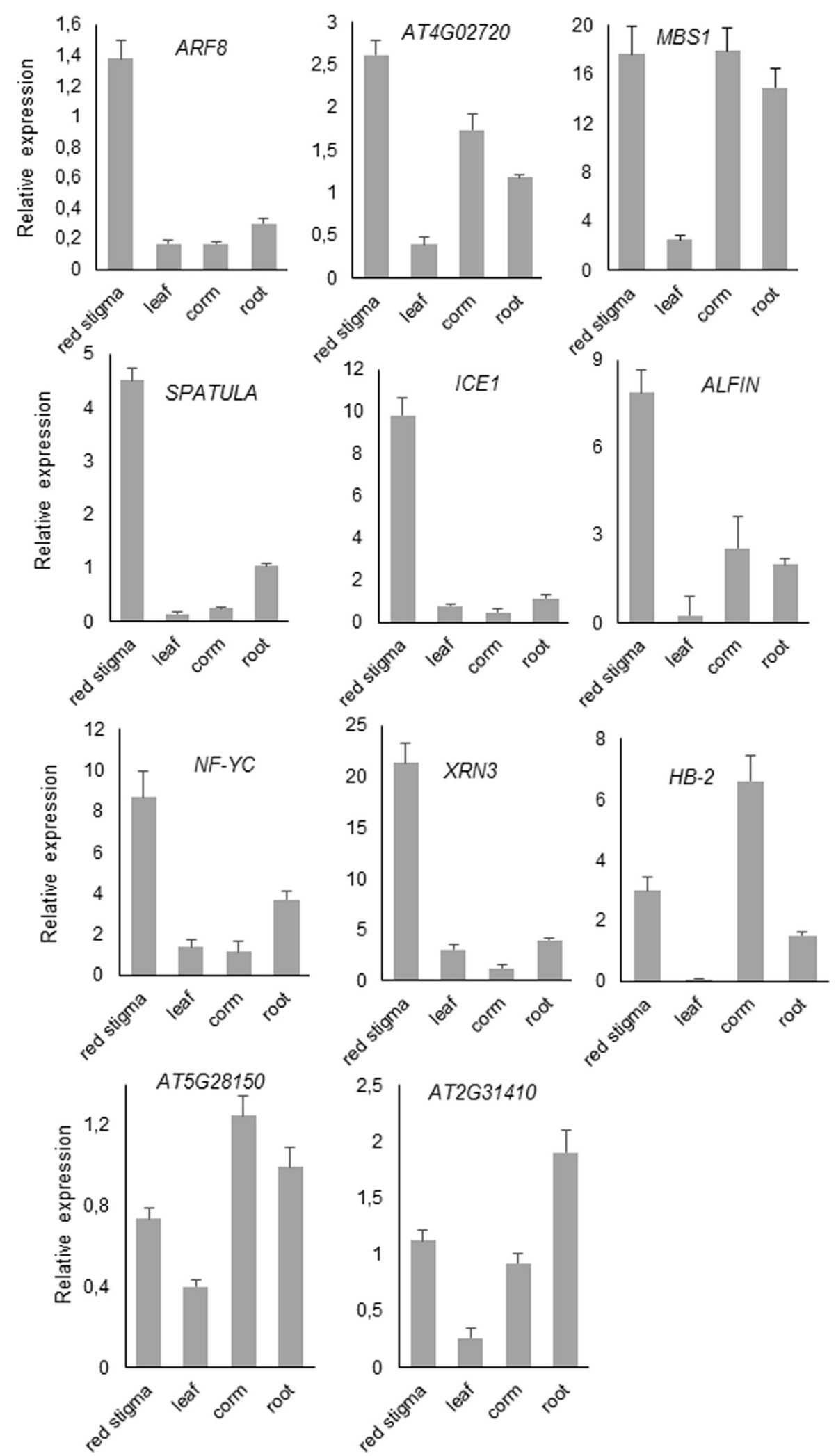

Fig. 5 Relative expression levels of the 11 TFs by qRT-PCR in different tissues from saffron 
accompanied by massive synthesis and accumulation of apocarotenoids and changes in plastid ultrastructure [39]. Environmental changes also have an important impact on carotenoid biosynthesis and accumulation. The accumulation of apocarotenoids and flower development in saffron are associated with cold [3,20], and both autumn and spring Crocus species produce and accumulate crocins during autumn-winter conditions in the Mediterranean area [25, 72]. In addition, in saffron and other Crocus species, synthesis and accumulation of crocins occurs in dark conditions [20,82], as does the accumulation of $\beta$-carotene in carrot [83], and lycopene in some cultivars of red grapefruits kept in the dark [84], confirming how light modulates a complex network of signals connecting carotenoid biosynthesis, storage, and plastid development [85]. In addition, in this study TFs involved in retrograde signaling and epigenetic development have been identified. The network of signals generated by the plastid as it develops is known as retrograde signaling, and certain apocarotenoids act as signals in plastid-to-nucleus signaling [86]. However, not much is known about this network during the biogenesis of chromoplasts. By contrast, the role of epigenetic mechanisms in the control of carotenoid regulation is now well stablished [16, 87], therefore similar modes of regulation of apocarotenogenesis should also be present in plants.

\section{Methods}

\section{Plant materials}

Stigmas collected at different developmental stages were obtained from C. sativus, C. ancyrensis and C. cartwrightianus; also, leaves, roots and cormlets were collected from C. sativus grown under field conditions in the Botanical Garden of Castilla-La Mancha (Albacete, Spain). The tissues were dissected and frozen in liquid nitrogen and stored at $-80^{\circ} \mathrm{C}$ until required.

\section{Extraction and analysis of crocins by UPLC-ESI-MS}

Dissected samples from stigmas at two developmental stages were ground in liquid nitrogen with a mixer mill MM400 (Retsch GmbH, Haan, Germany), extracted with $30 \% \mathrm{MeOH}$ and incubated for $10 \mathrm{~min}$ on ice. After centrifugation at $3000 \mathrm{~g}$ for $5 \mathrm{~min}$ at $4{ }^{\circ} \mathrm{C}$, the supernatants were saved and stored at $-80^{\circ} \mathrm{C}$ until further analysis by UPLC-ESI-MS. The UHPLC method used for the analysis and detection of crocetin, crocins and picrocrocin has been previously described [25]. In brief, a UPLC-PDA-qTOF-MS instrument (Waters, Spain) was used for compound separation and identification. Chromatographic separation was carried out on an Acquity BEH C18 column $(150 \times 2.1 \mathrm{~mm}$ i.d., $1.7 \mu \mathrm{m})$, with mobile phases consisting of formic acid : water $(1: 1000, v /$ $\mathrm{v}$; phase A) and formic acid : acetonitrile $(1: 1000, \mathrm{v} / \mathrm{v}$; phase B), in a gradient method of $80 \%$ A for $5 \mathrm{~min}, 80$ to $25 \% \mathrm{~A}$ in $15 \mathrm{~min}, 25$ to $0 \% \mathrm{~A}$ in $1 \mathrm{~min}$, hold at $100 \% \mathrm{~B}$ for $9 \mathrm{~min}$, and equilibration with $80 \% \mathrm{~A}$ for $4 \mathrm{~min}$. The injection volume was $5 \mu \mathrm{L}$ and the flow rate was $0.4 \mathrm{~mL} /$ min. Column and sample temperatures were $40^{\circ} \mathrm{C}$ and $10^{\circ} \mathrm{C}$, respectively. UV-VIS spectra were acquired in the $\lambda$ range $210-600 \mathrm{~nm}$. The MS parameters were as follows: cone voltage, $30 \mathrm{~V}$; capillary voltage, $3000 \mathrm{~V}$; source temperature, $120^{\circ} \mathrm{C}$; desolvation temperature, $300{ }^{\circ} \mathrm{C}$; cone gas flow, $50 \mathrm{~L} / \mathrm{h}$; desolvation gas flow, $500 \mathrm{~L} / \mathrm{h}$. MS data were acquired in centroid mode with a $\mathrm{m} / z$ range of 100-2000 with a scan and interscan time of $0.32 \mathrm{~s}$ and $0.1 \mathrm{~s}$, respectively. MassLynx version 4.1 and Q-tof Micro version 4.1 (Waters, Spain) were used to control the instruments and calculate accurate masses. All the assays were performed in triplicate.

\section{Sample RNA extraction for sequencing}

The RNA was extracted from stigmas at white (SI) and yellow (SII) stages using the Direct-zol Kit (Zymo Research, Freiburg, Germany). The obtained ARNs were quantified and between 10 to $15 \mu \mathrm{g}$ from white and yellow stigmas were sent to Macrogen Inc. (Seoul, South Korea; www.macrogen.com) to be used for the construction of the libraries and further library sequencing. TruSeq RNA Sample Prep kit (Illumina, San Diego, USA) was used for the construction of the libraries corresponding to the three species and obtained from two different developmental stages of the stigmas. A HiSeq 2000 sequencer (Illumina) was used to generate inward paired-end reads of $100 \mathrm{bp}$.

Data processing, transcriptome assembly and annotation Adaptors and sequencing artifacts as well as low quality fragments were trimmed from all the obtained RNA-seq data using the NGS QC Toolkit. The high-quality reads were in silico normalized prior to de novo assembly in order to reduce the sequencing coverage of regions highly represented with a fragment density $>30 \times$. Using this approach, the computational complexity was simplified keeping the quality of the assembled transcriptomes. The obtained sequences were assembled selecting a minimum fragment overlap of $40 \mathrm{bp}$, by using the de novo transcriptome assembler tool kit from Trinity [88]. Only those unigenes $>300 \mathrm{bp}$ were included in the assembled transcriptomes and used for differential expression analyses, and gene ontology (GO) sequence annotation using Blast2Go [89].

\section{Analysis of differentially expressed transcripts}

Employing the assembled six transcriptomes as a reference for $C$. sativus, the annotated libraries were subjected to transcriptome expression analysis. The six obtained libraries were analyzed using Bowtie (http://bowtie-bio.sourceforge.net/) [90]. The relative abundances of the aligned reads were estimated by 
using Cufflinks v.2.1.1 (http://cole-trapnell-lab.github. io/cufflinks/). Next, RNA-seq fragment counts were calculated by the unit of fragments per kilobase of exon per million fragments mapped (FPKM). A gene was considered expressed at low levels when for FPKM $\leq 2$, moderately expressed for FPKM $>2$ and $\leq$ 10 , and highly expressed for FPKM $>10$. For differential expression analysis, the values of $\log 2($ FPKM+1) were calculated, and these were normalized by quantile normalization. The $P$-values were acquired by t-test between each sample, and fold changes were computed with the mean $\log 2(\mathrm{FPKM}+1)$ values, gene by gene. R 2.14.1 (http://www.r-project.org) was used for differential expression analyses [91]. Differential expression between the two stigma stages was screened by detecting genes with statistical significance. In addition, the count matrix obtained for the sequenced samples was used to calculate a Euclidian distance matrix, which was used for hierarchical sample clustering. To identify the transcription factors (TFs), the assembled reads were searched against known TFs, as grouped in Plant Transcription Factor Database (PlnTFDB), using default parameters and a cut-off E-value of $1 \mathrm{e}^{-5}$. PlnTFDB is an integrative library of plant TFs which offers complete lists of TF families from plants with fully sequenced genomes. The identified candidate transcription factors were validated in PlantTFcat (http://plantgrn.noble.org/ PlantTFcat/).

\section{qRT-PCR analysis}

For qRT-PCR analysis, total RNA ( $2 \mu \mathrm{g})$ from stigmas (red), leaves, roots and corms, was treated with RQ1 DNase (Promega, Madisson, USA) and reverse-transcribed using First-Strand cDNA Synthesis Kit (GE Healthcare Life Sciences, Buckinghamshire, UK) according to manufacturer's instructions. The synthesized cDNAs were used for quantitative real-time PCR in a StepOne ${ }^{\mathrm{Tm}}$ Thermal Cycler (Applied Biosystems, Foster City, California, USA). All reactions were performed in triplicate containing $10 \mathrm{ng}$ of cDNA, LightCycler 480 SYBR Green I Master (Roche), and $0.2 \mu \mathrm{M}$ specific primers (Additional file 2: Table S4) in a final volume of $10 \mu \mathrm{l}$. The results were analysed using StepOne software v2.0 (Applied Biosystems, Foster City, California, USA). The relative expression levels of the analysed target genes were normalized to that of the reference gene18 S rRNA as described previously [9].

\section{Additional files}

Additional file 1: Figure S1. FPKM values distribution in the six analysed transcriptomes. Figure S2. Molecular interaction network of the 11 TFs identified as upregulated in all the Crocus transcriptomes in SII. Nodes represent proteins. The colored nodes are query proteins and first shell of interactors, and those which are filled is because its $3 \mathrm{D}$ structure is known or predicted. Interactions were produced using http://string-db.org. (PDF $643 \mathrm{~kb}$ )

Additional file 2: Table S1. TFs identified in the transcriptome analysis of stages I and II of Crocus sativus. Table S2. Up-regulated TFs in the SII/ SI developmental stages of saffron. Table S3. Down-regulated TFs in the SII/SI developmental stages of saffron. Table S4. Oligonucleotide sequences used for qRT-PCR. (PDF $134 \mathrm{~kb}$ )

\section{Abbreviations}

ALDH: aldehyde dehydrogenase; BCH: ( $\beta$-carotene hydroxylase; CCD2: carotenoid cleavage dioxygenase 2; CDP-ME: 4-diphosphocytidyl-2Cmethyl-d-erythritol; CDP-MEP: 4-diphosphocytidyl-2C-methyl-d-erythritol 2phosphate; CrtISO: carotene isomerase; DMAPP: dimethylallyl pyrophosphate; DXP: 1-deoxy-d-xylulose-5 phosphate; DXR: 1-deoxy-d-xylulose 5-phosphate reductoisomerase; DXS: 1-deoxy-d-xylulose-5-phosphate; GAP: d-glyceraldehyde 3-phosphate; HDR: 1-hydroxy-2-methyl-2-(E)-butenyl 4-diphosphate reductase; HDS: 1-hydroxy-2-methyl-2-(E)-butenyl 4-diphosphate synthase; HMBPP: 1hydroxy-2-methyl-2-(E)-butenyl 4-diphosphate; IDI: isopentenyl diphosphate isomerase; IPP: isopentenyl diphosphate; LCYB: Iycopene- $\beta$-cyclase; MCT: 2Cmethyl-d-erythritol 4-phosphate cytidyl transferase; MDS: 2C-methyl-d-erythritol 2,4-cyclodiphosphate synthase; ME-cPP: 2C-methyl-d-erythritol 2,4cyclodiphosphate; MEP: 2C-methyl-d-erythritol 4 phosphate; PDS: phytoene desaturase; PDS: phytoene synthase; PSY: phytoene synthase; Pyr: pyruvate; UGT74AD2: Crocus sativus glucosyltransferase 2; ZDS: Z-carotene desaturase; ZISO: 15-cis-Z-carotene isomerase

\section{Acknowledgments}

The laboratory participates in the CARNET network (BIO2015-71703-REDT and BIO2017-90877-RED) and in the European COST action CA15136 (EUROCAROTEN).

\section{Funding}

This work was supported by grants from the Spanish Ministerio de Economía y Competitividad (BIO2013-44239-R) and (BIO2016-77000-R).

\section{Availability of data and materials}

The datasets supporting the conclusions of this article are available in the SRA accession: PRJNA508499.

\section{Data availability}

The raw Illumina data generated in this study were deposited in the NCBI Sequence Read Archive (SRA) under accession number: PRJNA508499.

\section{Authors' contributions}

LG-G and OA designed the research, analysed the data and wrote the paper. AF performed the data analyses. ARM, AR and JA dissected the tissues, performed the RNA extraction and purification, and the expression analyses under the guidance of RC and OA. All authors discussed the data and reviewed and commented on the manuscript. All authors read and approved the final manuscript.

Ethics approval and consent to participate Not applicable.

Consent for publication

Not applicable.

\section{Competing interests}

The authors declare that they have no competing interests.

\section{Publisher's Note}

Springer Nature remains neutral with regard to jurisdictional claims in published maps and institutional affiliations.

\section{Author details}

${ }^{1}$ Instituto Botánico, Departamento de Ciencia y Tecnología Agroforestal y Genética, Universidad de Castilla-La Mancha, Campus Universitario s/n, 02071 
Albacete, Spain. ${ }^{2}$ Italian National Agency for New Technologies, Energy, and Sustainable Development, Casaccia Research Centre, 00123 Rome, Italy. ${ }^{3}$ VITAB Laboratorios. Polígono Industrial Garysol C/ Pino, parcela 53, 02110 La Gineta, Albacete, Spain.

\section{Received: 29 December 2018 Accepted: 8 April 2019}

\section{Published online: 27 April 2019}

\section{References}

1. Rodriguez-Concepcion M, Avalos J, Bonet ML, Boronat A, Gomez-Gomez L, Hornero-Mendez D, Limon MC, Melendez-Martinez AJ, Olmedilla-Alonso B, Palou A, et al. A global perspective on carotenoids: metabolism, biotechnology, and benefits for nutrition and health. Prog Lipid Res. 2018; 70:62-93.

2. Hou X, Rivers J, Leon P, McQuinn RP, Pogson BJ. Synthesis and function of Apocarotenoid signals in plants. Trends Plant Sci. 2016;21(9):792-803.

3. Ahrazem O, Rubio-Moraga A, Nebauer SG, Molina RV, Gomez-Gomez L. Saffron: its Phytochemistry, developmental processes, and biotechnological prospects. J Agric Food Chem. 2015;63(40):8751-64.

4. Pitsikas N: The Effect of Crocus sativus L. and Its Constituents on Memory: Basic Studies and Clinical Applications. Evid Based Complement Alternat Med 2015, 2015:926284.

5. Farkhondeh T, Samarghandian S, Shaterzadeh Yazdi H, Samini F. The protective effects of crocin in the management of neurodegenerative diseases: a review. Am J Neurodegener Dis. 2018;7(1):1-10.

6. Boskabady MH, Farkhondeh T. Antiinflammatory, antioxidant, and immunomodulatory effects of Crocus sativus L. and its Main constituents. Phytother Res. 2016;30(7):1072-94.

7. Winterhalter P, Straubinger M. Saffron-renewed interest in an ancient spice. Food Reviews International. 2000:16(1):39-59.

8. Frusciante $S$, Diretto $G$, Bruno M, Ferrante P, Pietrella M, Prado-Cabrero A, Rubio-Moraga A, Beyer P, Gomez-Gomez L, Al-Babili S, et al. Novel carotenoid cleavage dioxygenase catalyzes the first dedicated step in saffron crocin biosynthesis. Proc Natl Acad Sci U S A. 2014;111(33):12246-51.

9. Ahrazem O, Rubio-Moraga A, Berman J, Capell T, Christou P, Zhu C, GomezGomez L. The carotenoid cleavage dioxygenase CCD2 catalysing the synthesis of crocetin in spring crocuses and saffron is a plastidial enzyme. New Phytol. 2016;209(2):650-63.

10. Moraga AR, Nohales PF, Perez JA, Gomez-Gomez L. Glucosylation of the saffron apocarotenoid crocetin by a glucosyltransferase isolated from Crocus sativus stigmas. Planta. 2004;219(6):955-66.

11. Castillo R, Fernandez JA, Gomez-Gomez L. Implications of carotenoid biosynthetic genes in apocarotenoid formation during the stigma development of Crocus sativus and its closer relatives. Plant Physiol. 2005;139(2):674-89.

12. Ahrazem O, Rubio-Moraga A, Lopez RC, Gomez-Gomez L. The expression of a chromoplast-specific lycopene beta cyclase gene is involved in the high production of saffron's apocarotenoid precursors. J Exp Bot. 2010;61(1):105-19.

13. Moraga AR, Rambla JL, Ahrazem O, Granell A, Gomez-Gomez L. Metabolite and target transcript analyses during Crocus sativus stigma development. Phytochemistry. 2009;70(8):1009-16.

14. Ahrazem O, Rubio-Moraga A, Jimeno ML, Gomez-Gomez L. Structural characterization of highly glucosylated crocins and regulation of their biosynthesis during flower development in Crocus. Front Plant Sci. 2015;6:971.

15. Ahrazem O, Argandona J, Fiore A, Aguado C, Lujan R, Rubio-Moraga A, Marro M, Araujo-Andrade C, Loza-Alvarez P, Diretto G, et al. Transcriptome analysis in tissue sectors with contrasting crocins accumulation provides novel insights into apocarotenoid biosynthesis and regulation during chromoplast biogenesis. Sci Rep. 2018;8(1):2843.

16. Cazzonelli Cl, Pogson BJ. Source to sink: regulation of carotenoid biosynthesis in plants. Trends Plant Sci. 2010;15(5):266-74.

17. Nisar N, Li L, Lu S, Khin NC, Pogson BJ. Carotenoid metabolism in plants. Mol Plant. 2015;8(1):68-82.

18. Sun T, Yuan H, Cao H, Yazdani M, Tadmor Y, Li L. Carotenoid metabolism in plants: the role of plastids. Mol Plant. 2018;11(1):58-74.

19. Yuan H, Zhang J, Nageswaran D, Li L. Carotenoid metabolism and regulation in horticultural crops. Hortic Res. 2015;2:15036.

20. Ahrazem O, Rubio-Moraga A, Argandona-Picazo J, Castillo R, Gomez-Gomez L. Intron retention and rhythmic diel pattern regulation of carotenoid cleavage dioxygenase 2 during crocetin biosynthesis in saffron. Plant Mol Biol. 2016;91(3):355-74.
21. Jain $M$, Srivastava PL, Verma M, Ghangal R, Garg R. De novo transcriptome assembly and comprehensive expression profiling in Crocus sativus to gain insights into apocarotenoid biosynthesis. Sci Rep. 2016;6:22456.

22. Baba SA, Mohiuddin T, Basu S, Swarnkar MK, Malik AH, Wani ZA, Abbas N, Singh AK, Ashraf N. Comprehensive transcriptome analysis of Crocus sativus for discovery and expression of genes involved in apocarotenoid biosynthesis. BMC Genomics. 2015;16(1):698.

23. Nemati Z, Blattner FR, Kerndorff H, Erol O, Harpke D. Phylogeny of the saffron-crocus species group, Crocus series Crocus (Iridaceae). Mol Phylogenet Evol. 2018;127:891-7.

24. Rubio-Moraga A, Castillo-López R, Gómez-Gómez L, Ahrazem O. Saffron is a monomorphic species as revealed by RAPD, ISSR and microsatellite analyses. BMC Research Notes. 2009;2:189.

25. Rubio Moraga A, Ahrazem O, Rambla JL, Granell A, Gomez Gomez L. Crocins with high levels of sugar conjugation contribute to the yellow colours of early-spring flowering crocus tepals. PLoS One. 2013;8(9):e71946.

26. Ashburner M, Ball CA, Blake JA, Botstein D, Butler H, Cherry JM, Davis AP, Dolinski K, Dwight SS, Eppig JT, et al. Gene ontology: tool for the unification of biology. The Gene Ontology Consortium Nat Genet. 2000; 25(1):25-9.

27. Brioudes F, Thierry AM, Chambrier P, Mollereau B, Bendahmane M. Translationally controlled tumor protein is a conserved mitotic growth integrator in animals and plants. Proc Natl Acad Sci U S A. 2010;107(37):16384-9.

28. Flores-Perez $\mathrm{U}$, Jarvis P. Molecular chaperone involvement in chloroplast protein import. Biochim Biophys Acta. 2013;1833(2):332-40.

29. Gomez-Gomez L, Feo-Brito F, Rubio-Moraga A, Galindo PA, Prieto A, Ahrazem $O$. Involvement of lipid transfer proteins in saffron hypersensitivity: molecular cloning of the potential allergens. J Investig Allergol Clin Immunol. 2010;20(5):407-12.

30. Edqvist J, Blomqvist K, Nieuwland J, Salminen TA. Plant lipid transfer proteins: are we finally closing in on the roles of these enigmatic proteins? J Lipid Res. 2018;59(8):1374-82.

31. Mertens J, Aliyu H, Cowan DA: LEA Proteins and the Evolution of the WHy Domain. Appl Environ Microbiol 2018, 84(15).

32. Romera-Branchat M, Andrés F, Coupland G. Flowering responses to seasonal cues: what's new? Curr Opin Plant Biol. 2014;21:120-7.

33. Rodriguez-Concepcion M, Boronat A. Breaking new ground in the regulation of the early steps of plant isoprenoid biosynthesis. Curr Opin Plant Biol. 2015;25:17-22.

34. Banerjee A, Sharkey TD. Methylerythritol 4-phosphate (MEP) pathway metabolic regulation. Nat Prod Rep. 2014;31(8):1043-55.

35. Rubio A, Rambla JL, Santaella M, Gomez MD, Orzaez D, Granell A, GomezGomez L. Cytosolic and plastoglobule-targeted carotenoid dioxygenases from Crocus sativus are both involved in beta-ionone release. J Biol Chem. 2008;283(36):24816-25.

36. Rubio-Moraga A, Ahrazem O, Perez-Clemente RM, Gomez-Cadenas A, Yoneyama K, Lopez-Raez JA, Molina RV, Gomez-Gomez L. Apical dominance in saffron and the involvement of the branching enzymes CCD7 and CCD8 in the control of bud sprouting. BMC Plant Biol. 2014;14:171.

37. Rubio-Moraga A, Rambla JL, Fernandez-de-Carmen A, Trapero-Mozos A, Ahrazem O, Orzaez D, Granell A, Gomez-Gomez L. New target carotenoids for CCD4 enzymes are revealed with the characterization of a novel stressinduced carotenoid cleavage dioxygenase gene from Crocus sativus. Plant Mol Biol. 2014;86(4-5):555-69.

38. Alagoz Y, Nayak P, Dhami N. Cazzonelli Cl: cis-carotene biosynthesis, evolution and regulation in plants: the emergence of novel signaling metabolites. Arch Biochem Biophys. 2018;654:172-84.

39. Gomez-Gomez L, Parra-Vega V, Rivas-Sendra A, Segui-Simarro JM, Molina RV, Pallotti C, Rubio-Moraga A, Diretto G, Prieto A, Ahrazem O: Unraveling Massive Crocins Transport and Accumulation through Proteome and Microscopy Tools during the Development of Saffron Stigma. Int J Mol Sci 2017, 18(1).

40. Demurtas OC, Frusciante S, Ferrante P, Diretto G, Azad NH, Pietrella M, Aprea G, Taddei AR, Romano E, Mi J, et al. Candidate enzymes for saffron Crocin biosynthesis are localized in multiple cellular compartments. Plant Physiol. 2018;177(3):990-1006.

41. Gomez-Gomez L, Pacios LF, Diaz-Perales A, Garrido-Arandia M, Argandona J, Rubio-Moraga A, Ahrazem O: Expression and Interaction Analysis among Saffron ALDHs and Crocetin Dialdehyde. Int J Mol Sci 2018, 19(5).

42. Trautmann D, Beyer P, Al-Babili S. The ORF slr0091 of Synechocystis sp. PCC6803 encodes a high-light induced aldehyde dehydrogenase converting apocarotenals and alkanals. FEBS J. 2013;280(15):3685-96. 
43. Ramsay NA, Glover BJ. MYB-bHLH-WD40 protein complex and the evolution of cellular diversity. Trends Plant Sci. 2005;10(2):63-70.

44. Pires N, Dolan L. Origin and diversification of basic-helix-loop-helix proteins in plants. Mol Biol Evol. 2010;27(4):862-74.

45. Ambawat S, Sharma P, Yadav NR, Yadav RC. MYB transcription factor genes as regulators for plant responses: an overview. Physiol Mol Biol Plants. 2013; 19(3):307-21.

46. Nijhawan A, Jain M, Tyagi AK, Khurana JP. Genomic survey and gene expression analysis of the basic leucine zipper transcription factor family in Rice. Plant Physiol. 2008;146(2):333-50.

47. Zhang $X$, Ji Y, Xue C, Ma H, Xi Y, Huang P, Wang H, An F, Li B, Wang $Y$, et al. Integrated regulation of apical hook development by transcriptional coupling of EIN3/EIL1 and PIFs in Arabidopsis. Plant Cell. 2018;30(9):1971-88.

48. Farre EM, Kay SA. PRR7 protein levels are regulated by light and the circadian clock in Arabidopsis. Plant J. 2007;52(3):548-60.

49. Salome PA, To JP, Kieber JJ, McClung CR. Arabidopsis response regulators ARR3 and ARR4 play cytokinin-independent roles in the control of circadian period. Plant Cell. 2006;18(1):55-69.

50. Ashraf N, Jain D, Vishwakarma RA. Identification, cloning and characterization of an ultrapetala transcription factor CsULT1 from Crocus: a novel regulator of apocarotenoid biosynthesis. BMC Plant Biol. 2015;15:25.

51. Malik AH, Ashraf N. Transcriptome wide identification, phylogenetic analysis, and expression profiling of zinc-finger transcription factors from Crocus sativus L. Mol Gen Genomics. 2017;292(3):619-33.

52. Masaki T, Tsukagoshi H, Mitsui N, Nishii T, Hattori T, Morikami A, Nakamura K. Activation tagging of a gene for a protein with novel class of CCTdomain activates expression of a subset of sugar-inducible genes in Arabidopsis thaliana. Plant J. 2005;43(1):142-52.

53. Ikeda M, Mitsuda N, Ohme-Takagi M. ATBS1 INTERACTING FACTORs negatively regulate Arabidopsis cell elongation in the triantagonistic bHLH system. Plant Signal Behav. 2013;8(3):e23448.

54. Guilfoyle TJ, Hagen G. Auxin response factors. Curr Opin Plant Biol. 2007; 10(5):453-60.

55. Reeves PH, Ellis CM, Ploense SE, Wu MF, Yadav V, Tholl D, Chetelat A, Haupt I, Kennerley BJ, Hodgens C, et al. A regulatory network for coordinated flower maturation. PLoS Genet. 2012;8(2):e1002506.

56. Kang C, He S, Zhai H, Li R, Zhao N, Liu Q. A Sweetpotato auxin response factor gene (IbARF5) is involved in carotenoid biosynthesis and salt and drought tolerance in transgenic Arabidopsis. Front Plant Sci. 2018;9:1307.

57. Wu L, Tian Z, Zhang J. Functional dissection of auxin response factors in regulating tomato leaf shape development. Front Plant Sci. 2018;9:957.

58. Ye J, Hu T, Yang C, Li H, Yang M, ljaz R, Ye Z, Zhang Y. Transcriptome profiling of tomato fruit development reveals transcription factors associated with ascorbic acid, Carotenoid and Flavonoid Biosynthesis. PLoS One. 2015;10(7):e0130885.

59. Li R, Zhai H, Kang C, Liu D, He S, Liu Q. De novo transcriptome sequencing of the Orange-fleshed sweet potato and analysis of differentially expressed genes related to carotenoid biosynthesis. Int J Genomics. 2015;2015:843802.

60. Goetz M, Hooper LC, Johnson SD, Rodrigues JC, Vivian-Smith A, Koltunow AM. Expression of aberrant forms of AUXIN RESPONSE FACTOR8 stimulates parthenocarpy in Arabidopsis and tomato. Plant Physiol. 2007;145(2):351-66.

61. Groszmann M, Paicu T, Smyth DR. Functional domains of SPATULA, a bHLH transcription factor involved in carpel and fruit development in Arabidopsis. Plant J. 2008;55(1):40-52.

62. Baumberger N, Baulcombe DC. Arabidopsis ARGONAUTE1 is an RNA slicer that selectively recruits microRNAs and short interfering RNAs. Proc Natl Acad Sci U S A. 2005;102(33):11928-33.

63. Liu C, Xin Y, Xu L, Cai Z, Xue Y, Liu Y, Xie D, Qi Y. Arabidopsis ARGONAUTE 1 binds chromatin to promote gene transcription in response to hormones and stresses. Dev Cell. 2018;44(3):348-61 e347.

64. Shumbe L, D'Alessandro S, Shao N, Chevalier A, Ksas B, Bock R, Havaux M. METHYLENE BLUE SENSITIVITY 1 (MBS1) is required for acclimation of Arabidopsis to singlet oxygen and acts downstream of beta-cyclocitral. Plant Cell Environ. 2017:40(2):216-26.

65. Gou M, Hou G, Yang H, Zhang X, Cai Y, Kai G, Liu CJ. The MYB107 transcription factor positively regulates Suberin biosynthesis. Plant Physiol. 2017; 173(2):1045-58.
66. Krzyszton M, Zakrzewska-Placzek M, Kwasnik A, Dojer N, Karlowski W, Kufel J. Defective XRN3-mediated transcription termination in Arabidopsis affects the expression of protein-coding genes. Plant J. 2018;93(6):1017-31.

67. Gy I, Gasciolli V, Lauressergues D, Morel JB, Gombert J, Proux F, Proux C, Vaucheret H, Mallory AC. Arabidopsis FIERY1, XRN2, and XRN3 are endogenous RNA silencing suppressors. Plant Cell. 2007;19(11):3451-61.

68. Estavillo GM, Crisp PA, Pornsiriwong W, Wirtz M, Collinge D, Carrie C, Giraud E, Whelan J, David P, Javot H, et al. Evidence for a SAL1-PAP chloroplast retrograde pathway that functions in drought and high light signaling in Arabidopsis. Plant Cell. 2011;23(11):3992-4012.

69. Harris JC, Hrmova M, Lopato S, Langridge P. Modulation of plant growth by HD-zip class I and II transcription factors in response to environmental stimuli. New Phytol. 2011;190(4):823-37.

70. Zinati Z, Nazari L, Bagnaresi P, Ravash R. $<i>$ in silico $</ i>$ identification of transcription factors associated with the biosynthesis of carotenoids in corn (<i>Zea mays L.</i>). BioTechnologia. 2017;98(1):41-51.

71. Chinnusamy V, Ohta M, Kanrar S, Lee BH, Hong X, Agarwal M, Zhu JK. ICE1: a regulator of cold-induced transcriptome and freezing tolerance in Arabidopsis. Genes Dev. 2003;17(8):1043-54.

72. Molina RV, Valero M, Navarro Y, Guardiola JL, García-Luis A. Temperature effects on flower formation in saffron (Crocus sativus L.). Scientia Horticulturae. 2005;103(3):18.

73. Campbell R, Ducreux LJ, Morris WL, Morris JA, Suttle JC, Ramsay G, Bryan GJ, Hedley PE, Taylor MA. The metabolic and developmental roles of carotenoid cleavage dioxygenase4 from potato. Plant Physiol. 2010;154(2): 656-64.

74. Liang X, Lei M, Li F, Yang X, Zhou M, Li B, Cao Y, Gong S, Liu K, Liu J, et al. Family-wide characterization of histone binding abilities of PHD domains of AL proteins in Arabidopsis thaliana. Protein J. 2018.

75. Cazzonelli Cl, Cuttriss AJ, Cossetto SB, Pye W, Crisp P, Whelan J, Finnegan EJ, Turnbull C, Pogson BJ. Regulation of carotenoid composition and shoot branching in Arabidopsis by a chromatin modifying histone methyltransferase, SDG8. Plant Cell. 2009;21(1):39-53.

76. Arango J, Beltran J, Nunez J, Chavarriaga P. Evidence of epigenetic mechanisms affecting carotenoids. Subcell Biochem. 2016;79:295-307.

77. Chandrika NN, Sundaravelpandian K, Schmidt W. A PHD in histone language: on the role of histone methylation in plant responses to phosphate deficiency. Plant Signal Behav. 2013;8(6):e24381.

78. Zhao H, Wu D, Kong F, Lin K, Zhang H, Li G. The Arabidopsis thaliana nuclear factor $Y$ transcription factors. Front Plant Sci. 2016;7:2045.

79. Tang Y, Liu X, Liu X, Li Y, Wu K, Hou X. Arabidopsis NF-YCs mediate the light-controlled hypocotyl elongation via modulating histone acetylation. Mol Plant. 2017;10(2):260-73.

80. Li L, Yuan H. Chromoplast biogenesis and carotenoid accumulation. Arch Biochem Biophys. 2013;539(2):102-9.

81. Li L, Yuan H, Zeng Y, Xu Q. Plastids and carotenoid accumulation. Subcell Biochem. 2016;79:273-93.

82. Ahrazem O, Argandona J, Castillo R, Rubio-Moraga A, Gomez-Gomez L. Identification and cloning of differentially expressed SOUL and ELIP genes in saffron stigmas using a subtractive hybridization approach. PLoS One. 2016;11(12):e0168736.

83. Iorizzo $M$, Ellison $S$, Senalik D, Zeng P, Satapoomin P, Huang J, Bowman $M$, lovene $M$, Sanseverino W, Cavagnaro $P$, et al. A high-quality carrot genome assembly provides new insights into carotenoid accumulation and asterid genome evolution. Nat Genet. 2016;48(6):657-66.

84. Lado J, Zacarias L, Rodrigo MJ. Regulation of carotenoid biosynthesis during fruit development. Subcell Biochem. 2016;79:161-98.

85. Llorente B, Martinez-Garcia JF, Stange C, Rodriguez-Concepcion M. Illuminating colors: regulation of carotenoid biosynthesis and accumulation by light. Curr Opin Plant Biol. 2017;37:49-55.

86. Brunkard JO, Burch-Smith TM. Ties that bind: the integration of plastid signalling pathways in plant cell metabolism. Essays Biochem. 2018;62(1):95-107.

87. Liu R, How-Kit A, Stammitti L, Teyssier E, Rolin D, Mortain-Bertrand A, Halle S, Liu M, Kong J, Wu C, et al. A DEMETER-like DNA demethylase governs tomato fruit ripening. Proc Natl Acad Sci U S A. 2015;112(34): 10804-9.

88. Grabherr MG, Haas BJ, Yassour M, Levin JZ, Thompson DA, Amit Adiconis X, Fan L, Raychowdhury R, Zeng Q, et al. Full-length transcriptome assembly from RNA-Seq data without a reference genome. Nat Biotechnol. 2011;29(7):644-52. 
89. Conesa A, Gotz S, Garcia-Gomez JM, Terol J, Talon M, Robles M. Blast2GO: a universal tool for annotation, visualization and analysis in functional genomics research. Bioinformatics. 2005;21(18):3674-6.

90. Langmead B, Trapnell C, Pop M, Salzberg SL. Ultrafast and memory-efficient alignment of short DNA sequences to the human genome. Genome Biol. 2009:10(3):R25

91. Robinson MD, McCarthy DJ, Smyth GK. edgeR: a Bioconductor package for differential expression analysis of digital gene expression data. Bioinformatics. 2010;26(1):139-40.

Ready to submit your research? Choose BMC and benefit from:

- fast, convenient online submission

- thorough peer review by experienced researchers in your field

- rapid publication on acceptance

- support for research data, including large and complex data types

- gold Open Access which fosters wider collaboration and increased citations

- maximum visibility for your research: over $100 \mathrm{M}$ website views per year

At $\mathrm{BMC}$, research is always in progress.

Learn more biomedcentral.com/submissions 